I M M U N O L O G Y

\title{
Ubiquitin-dependent endocytosis of NKG2D-DAP10 receptor complexes activates signaling and functions in human NK cells
}

\author{
Linda Quatrini, ${ }^{1 \star}$ Rosa Molfetta, ${ }^{1}$ Beatrice Zitti, ${ }^{1}$ Giovanna Peruzzi, ${ }^{2}$ \\ Cinzia Fionda, ${ }^{1}$ Cristina Capuano, ${ }^{3}$ Ricciarda Galandrini, ${ }^{3}$ Marco Cippitelli, ${ }^{1}$ \\ Angela Santoni, ${ }^{1,4 \dagger}$ Rossella Paolini ${ }^{1,4 \dagger}$
}

\begin{abstract}
Cytotoxic lymphocytes share the presence of the activating receptor NK receptor group 2, member D (NKG2D) and the signaling-competent adaptor DNAX-activating protein 10 (DAP10), which together play an important role in antitumor immune surveillance. Ligand stimulation induces the internalization of NKG2D-DAP10 complexes and their delivery to lysosomes for degradation. In experiments with human NK cells and cell lines, we found that the ligand-induced endocytosis of NKG2D-DAP10 depended on the ubiquitylation of DAP10, which was also required for degradation of the internalized complexes. Moreover, through combined biochemical and microscopic analyses, we showed that ubiquitin-dependent receptor endocytosis was required for the activation of extracellular signal-regulated kinase (ERK) and NK cell functions, such as the secretion of cytotoxic granules and the inflammatory cytokine interferon- $\gamma$. These results suggest that NKG2D-DAP10 endocytosis represents a means to decrease cell surface receptor abundance, as well as to control signaling outcome in cytotoxic lymphocytes.
\end{abstract}

\section{INTRODUCTION}

Cytotoxic lymphocytes are major players in the immune surveillance of cancer, because they selectively kill malignant cells as a result of their ability to recognize molecules induced by neoplastic transformation. Different subsets of human cytotoxic lymphocytes, including natural killer (NK) cells, $\mathrm{CD}^{+} \alpha \beta \mathrm{T}$ cells, and $\gamma \delta \mathrm{T}$ cells, share the presence of the activating receptor NK receptor group 2, member D (NKG2D), which stimulates effector responses upon binding to its ligands (NKG2DLs): major histocompatibility complex (MHC) class I-related chain (MIC) A (MICA) and MICB, and UL16-binding proteins (ULBP1 to ULBP6) $(1,2)$. The increase in the cell surface abundances of NKG2DLs is driven by genotoxic stress and other forms of stress that are associated with malignant transformation (3), thus rendering damaged cells susceptible to NKG2D-mediated cellular cytotoxicity (4). The prominent role of this receptor in antitumor immune surveillance has been demonstrated by experiments with murine tumor models and NKG2D-deficient mice $(5,6)$.

NKG2D is a C-type lectin receptor, which is composed of two disulfidelinked type II transmembrane glycoproteins bearing a short intracellular tail that is not endowed with signaling capacity. Thus, to propagate signals, human NKG2D needs to couple to the transmembrane adaptor DNAXactivating protein 10 (DAP10), which together form a hexameric structure composed of one NKG2D homodimer assembled with two DAP10 homodimers (7). DAP10 contains in its cytoplasmic domain a tyrosine-based motif (YINM) that is involved in the recruitment of phosphatidylinositol 3-kinase (PI3K) and the complex between growth factor receptor-bound

\footnotetext{
'Department of Molecular Medicine, "Sapienza" University of Rome, 00161 Rome, Italy. ${ }^{2}$ Istituto Italiano di Tecnologia, CLNS@Sapienza, "Sapienza" University of Rome, 00161 Rome, Italy. ${ }^{3}$ Department of Experimental Medicine, "Sapienza" University of Rome, 00161 Rome, Italy. ${ }^{4}$ Istituto Pasteur-Fondazione Cenci Bolognetti, "Sapienza" University of Rome, 00161 Rome, Italy.

*Present address: Centre d'Immunologie de Marseille-Luminy, Aix Marseille Université UM2, INSERM, U1104, CNRS UMR7280, 13288 Marseille, France. †Corresponding author. E-mail: rossella.paolini@uniroma1.it (R.P.); angela. santoni@uniroma1.it (A.S.)
}

protein 2 (Grb2) and the guanine nucleotide exchange factor Vav1 (8-10). This activating motif is similar to those found in costimulatory receptors, such as CD28, inducible costimulator (ICOS), and CD19 $(11,12)$. Indeed, NKG2D provides a costimulatory rather than a stimulatory signal to activated $T$ cells, acting in concert with other costimulatory molecules to modify the strength and duration of antigen-specific responses mediated by the T cell receptor (TCR). In NK cells, the functional outcome is the result of the integration of signals from a broad array of activating and inhibitory receptors $(13,14)$, and $\mathrm{NKG} 2 \mathrm{D}$ functions either as costimulatory or a stimulatory receptor depending on the activation status of the cell (15). Activation of NKG2D on NK cells contributes to the innate immune response through the ability of the receptor to stimulate cytotoxicity against NKG2DL-bearing target cells, as well as to induce the production of various chemokines and cytokines, including interferon- $\gamma($ IFN- $\gamma$ ) (16).

Numerous studies have reported that persistent exposure to NKG2DLs located on the surface of tumor cells, or released either in exosomes or as soluble molecules by proteolytic shedding, can decrease the cell surface abundance of receptors, which leads to the impairment of NKG2Ddependent antitumor functions of both NK cells and $\mathrm{CD}^{+} \mathrm{T}$ cells (17-21). Receptor internalization and degradation upon ligand binding is a welldocumented means to dampen immune responses and excessive inflammation: by limiting the availability of activating receptors on the cell surface, cells become refractory to additional stimuli. Internalization and degradation of several immune receptors are dependent on the ubiquitin pathway (22-26). In addition, endocytosis of some membrane receptors is now recognized as an important route that is instrumental for signal transduction $(27,28)$. Several studies conducted on receptor tyrosine kinases (RTKs) and heterotrimeric guanine nucleotide-binding protein ( $\mathrm{G}$ protein)-coupled receptors (GPCRs) have demonstrated that endocytosis is required to bring activated receptors in close proximity to key signaling components, including mitogen-activated protein kinases (MAPKs), located in endosomes, thereby enabling signal propagation (29-34).

In the case of immune receptors, endosomes could participate in both $\mathrm{B}$ cell and T cell signaling (35-39); however, little is currently known 
about the role that immune receptor endocytosis plays in controlling signaling and the functional responses of immune cells. With respect to the NKG2D-DAP10 complex, we previously demonstrated that NKG2D in human NK cells is subjected to internalization and subsequent lysosomal degradation upon ligand binding and that this process depends on ubiquitylation (26); however, whether DAP10 can undergo ubiquitylation and whether receptor endocytosis contributes to signaling are unclear. Here, we found that the engagement of NKG2D on NK cells resulted in the ubiquitylation of DAP10, which was required for the endocytosis and degradation of the NKG2D-DAP10 complex. Moreover, we demonstrated that signaling was initiated at the plasma membrane and then continued after the engaged NKG2D-DAP10 complexes were internalized and had trafficked to endosomes, which led to NK cell functional responses.

\section{RESULTS}

DAP10 undergoes ubiquitylation upon NKG2D engagement We previously demonstrated the contribution of the ubiquitin pathway in the internalization and degradation of $\mathrm{NKG} 2 \mathrm{D}$ upon stimulation with MICA-expressing target cells (26). Here, we investigated whether the NKG2DDAP10 complex underwent ubiquitylation. Because of the difficulty in detecting endogenous DAP10 with commercially available antibodies, we transfected the human NK cell line NKL with a plasmid encoding a green fluorescent protein (GFP)-tagged wild-type DAP10 to generate a stable cell line (DAP10WT-GFP NKL cells). These cells were mixed with target $\mathrm{Ba} / \mathrm{F} 3$ cells expressing MICA (Ba/F3-MICA cells) at a 1:1 ratio, and after stimulation, DAP10 was immunoprecipitated from the NKL cell lysates with an anti-GFP monoclonal antibody (mAb) (Fig. 1A). After 1 min of coincubation, in addition to a band corresponding to the DAP10-GFP fusion protein $(\sim 37 \mathrm{kD})$, Western blotting analysis revealed the presence of a specific activation-induced form of molecular mass $\sim 45 \mathrm{kD}$, which was compatible with the addition of a single ubiquitin moiety $(8.5 \mathrm{kD})$ and is characteristic of monoubiquitylation. The anti-ubiquitin $\mathrm{mAb}$ FK2 detects both monoand polyubiquitylated proteins (40), and in our hands, it recognized a band migrating at $\sim 45 \mathrm{kD}$, which suggested that DAP10 was monoubiquitylated (Fig. 1A). Moreover, additional bands of higher molecular mass were also detected with the anti-ubiquitin antibody (Fig. 1A). These bands could correspond to polyubiquitylated forms of DAP10 that were not revealed with the anti-GFP antibody because of their low abundance, or to ubiquitylated proteins that coimmunoprecipitated with DAP10. Samples subjected to immunoprecipitation with an isotype-matched control antibody did not show any reactivity at $\sim 45 \mathrm{kD}$ or greater (Fig. $1 \mathrm{~A}$ ). To confirm that DAP10 underwent ubiquitylation, we performed an in vitro ubiquitylation assay in which GFP-tagged DAP10 was immunoprecipitated from unstimulated DAP10WTGFP NKL cells (Fig. 1B). We observed a similar pattern of bands to those seen earlier (Fig. 1A). Together, these results indicate that DAP10 is ubiquitylated.

The amino acid residue sequence of DAP10 contains only one lysine residue (Lys ${ }^{84}$ ) (Fig. 1C). To investigate the role of DAP10 ubiquitylation, we generated an NKL cell line expressing a DAP10-GFP fusion protein in which Lys ${ }^{84}$ of DAP10 was mutated to an arginine (DAP10K84R). We first verified that this mutation did not alter the ability of DAP10(K84R) proteins to bind to NKG2D or to undergo phosphorylation in response to engagement of NKG2D (fig. S1, A and B). Furthermore, flow cytometric analysis revealed that comparable amounts of wild-type and mutant DAP10GFP fusion proteins were present in both cell lines and that the DAP10 mutant did not alter the amount of cell surface NKG2D or that of other activating receptors not associated with DAP10, such as 2B4 (fig. S1C). We then compared the pattern of DAP10 ubiquitylation in cells expressing either wild-type DAP10 or DAP10(K84R) (Fig. 1D). After 1 min of stimulation of the NKL cell lines with anti-NKG2D mAb, there was a substantial decrease in the intensity of the bands detected by the anti-ubiquitin antibody in samples from the DAP10(K84R)-GFP cells compared to those from the DAP10WT-GFP cells (Fig. 1D). These results indicate that Lys ${ }^{84}$ is the site of ubiquitylation of DAP10, and support the conclusion that the
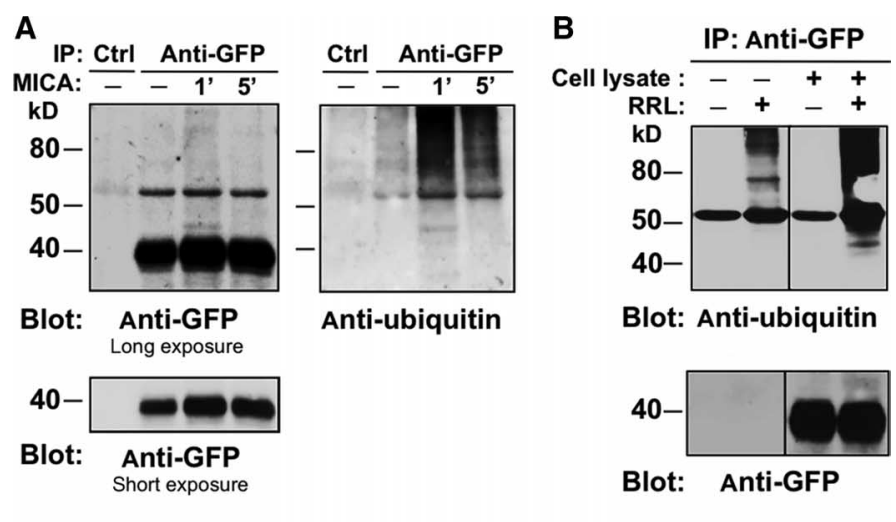

Blot: Anti-ubiquitin

C

>gi|5714436|gb|AAD47911.1|AF122904_1 membrane protein DAP10 [Homo sapiens] MIHLGHILFLLLLPVAAAQTTPGERSSLPAFYPGTSGSCSGCGSLSLPLLAGLVAA DAVASLLIVGAVFLCARPRRSPAQEDG@VYINMPGRG

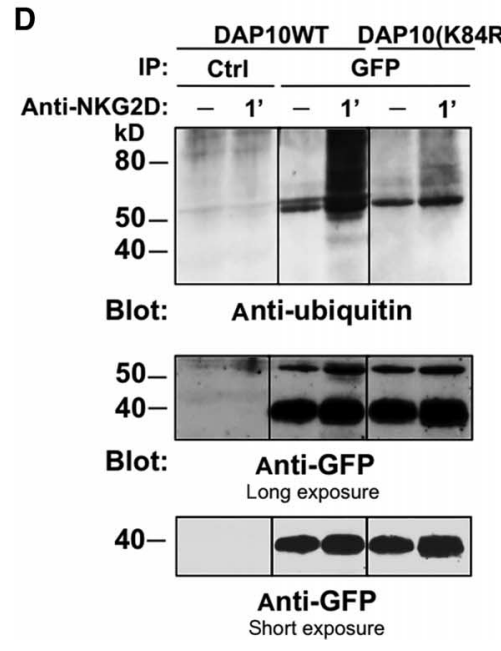

Fig. 1. DAP10 is ubiquitylated on Lys ${ }^{84}$ upon NKG2D engagement. (A) DAP10WT-GFP NKL cells and paraformaldehyde (PFA)-fixed Ba/F3-MICA cells were mixed at a $1: 1$ ratio, centrifuged for $1 \mathrm{~min}$ at $100 \mathrm{~g}$ to enable conjugate formation, and then left on ice (-) or incubated for the indicated times at $37^{\circ} \mathrm{C}$. Lysates were immunoprecipitated (IP) with anti-GFP mAb or isotypematched mAb (Ctrl). Immunoprecipitates were then analyzed by Western blotting with anti-GFP antibody (left) before being stripped and analyzed with anti-ubiquitin mAb (right). (B) DAP10WT-GFP $\mathrm{NKL}$ cell lysates were subjected to immunoprecipitation with anti-GFP antibody coupled to protein GSepharose beads. Immunoprecipitates and anti-GFP-conjugated protein G-Sepharose beads alone were incubated with or without rabbit reticulocyte lysate (RRL) in ubiquitylation buffer at $30^{\circ} \mathrm{C}$ for 2 hours. Samples were then washed with lysis buffer, resolved by SDS-polyacrylamide gel electrophoresis (PAGE), and analyzed by Western blotting with the indicated antibodies. (C) Amino acid sequence of the human DAP10 protein. The transmembrane region is underlined, the putative site of ubiquitylation $(\mathrm{K})$ is circled, and the activating YINM motif is in bold. (D) DAP10WT-GFP and DAP10(K84R)-GFP NKL cells were incubated with anti-NKG2D mAb and then left on ice (-) or incubated with goat anti-mouse lgG for $1 \mathrm{~min}$ at $37^{\circ} \mathrm{C}$ to activate NKG2D. Cell lysates were then subjected to immunoprecipitation and Western blotting analysis as described for $(A)$. Black vertical lines indicate noncontiguous blots. All Western blots are representative of two independent experiments. 
forms of higher molecular mass mainly represent polyubiquitylated DAP10 species.

\section{The DAP10(K84R) mutant inhibits both the internalization and degradation of NKG2D-DAP10}

To assess the effect of the K84R mutation on NKG2D-DAP10 internalization, we analyzed NKL transfectants using fluorescence microscopy upon stimulation with an anti-NKG2D mAb. In unstimulated cells, a uniform distribution of GFP was observed over the whole plasma membrane in cells expressing either DAP10WT-GFP or DAP10(K84R)-GFP (Fig. 2A). After $15 \mathrm{~min}$ of stimulation, DAP10WT-GFP protein was clearly

A

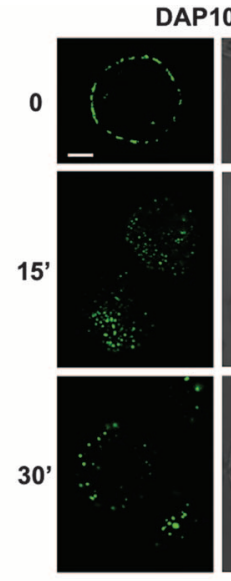

B

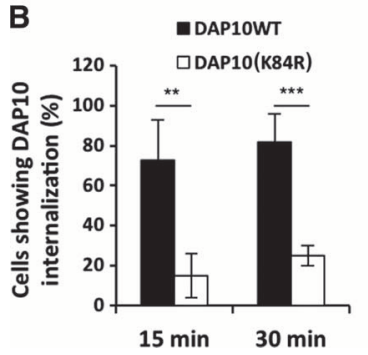

Fig. 2. DAP10 ubiquitylation is required for internalization of the NKG2DDAP10 complex. (A) DAP10WT-GFP and DAP10(K84R)-GFP NKL cells, as indicated, were incubated with anti-NKG2D mAb and then were left untreated on ice $(0)$ or were incubated with goat anti-mouse antibody for the indicated times at $37^{\circ} \mathrm{C}$. The cells were then plated on poly-L-lysine-coated coverslips, fixed, and washed before the coverslips were mounted and analyzed by fluorescence microscopy. Representative images of single cells are shown as a single optical section. Right: Differential interference contrast (DIC) images overlaid on the DAP10-GFP fluorescence images. Scale bar, $5 \mu \mathrm{m}$. Images are representative of three independent experiments. (B) The percentages of cells showing DAP10 internalization at the indicated times were calculated by analyzing randomly acquired fields for each time point ( $n=40$ cells). Data are means \pm SD of three independent experiments. ${ }^{\star \star} P<0.01$; ${ }^{* \star} P<0.005$ by Student's $t$ test. (C) DAP10WT-GFP and DAP10(K84R)-GFP NKL cells were incubated with anti-NKG2D mAb and then stimulated with Alexa Fluor 350-conjugated goat anti-mouse IgG (red) for $30 \mathrm{~min}$ at $37^{\circ} \mathrm{C}$. GFP fluorescence is in green. An overlay of the two-color merged images and the DIC image are also shown. Scale bar, $5 \mu \mathrm{m}$. Images are representative of three independent experiments. detected inside the cells, whereas DAP10(K84R)-GFP appeared to be clustered but was still associated with the plasma membrane (Fig. 2A). Analysis at a later time (30 min) revealed that DAP10WT-GFP was internalized in about $80 \%$ of cells, whereas DAP10(K84R)-GFP was still localized in clusters on the plasma membrane in most cells (Fig. 2, A and B). Similar results were obtained by analyzing NKG2D internalization in cells expressing either DAP10WT-GFP or DAP10(K84R)-GFP $30 \mathrm{~min}$ after stimulation (Fig. 2C), thus suggesting that mutation of DAP10 ubiquitylation site prevents the endocytosis of the engaged NKG2DDAP10 complex.

We previously demonstrated that stimulated NKG2D is internalized and then subjected to lysosomal degradation (26). Consistent with this finding, we found that engagement of NKG2D resulted in the degradation of both DAP10 and NKG2D in cells expressing DAP10WT-GFP, as revealed by decreased band intensities in samples from cells stimulated for $15 \mathrm{~min}$ (Fig. 3, A and B). In contrast, receptor degradation was less substantial in cells expressing DAP10(K84R). The lack of a complete inhibition of NKG2D degradation in DAP10(K84R)-expressing cells might be explained by the presence of an additional internalization motif within the cytoplasmic tail of NKG2D but may also depend on the internalization and degradation of NKG2D that was associated with endogenous DAP10. Together, these results support a role for DAP10 ubiquitylation in driving NKG2D-DAP10 internalization and sorting to lysosomes for degradation.

\section{DAP10 ubiquitylation is required for NKG2D-mediated ERK1/2 activation and NK cell functions}

Several studies showed that the endocytosis of activated receptors is required not only to decrease their cell surface abundance but also to form specialized molecular platforms responsible for additional signal outputs (31-33); however, whether NKG2D internalization is necessary for signal
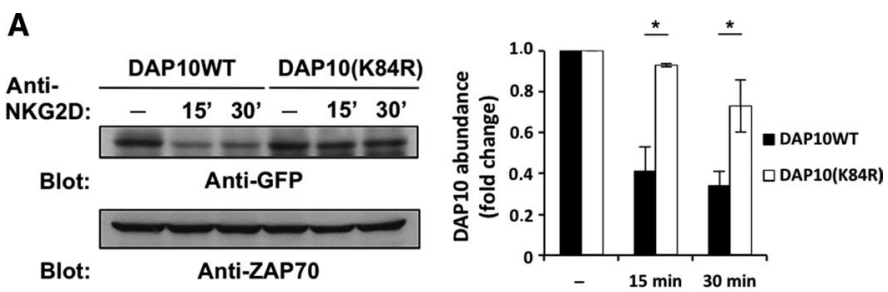

B
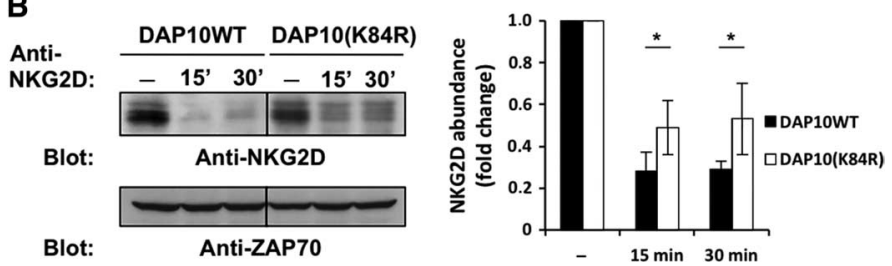

Fig. 3. DAP10 ubiquitylation is required for degradation of the NKG2DDAP10 complex. (A and B) DAP10WT-GFP and DAP10(K84R)-GFP NKL cells were left unstimulated or were incubated with anti-NKG2D mAb and goat anti-mouse lgG for the indicated times. Left: Whole-cell lysates were then analyzed by Western blotting with the indicated antibodies. Black vertical lines indicate noncontiguous blots. Western blots are from a single experiment and are representative of three experiments. Right: The abundances of the DAP10 (A) and NKG2D (B) proteins, normalized to that of ZAP70, were determined by densitometric analysis and are expressed relative to the protein abundances of unstimulated cells (arbitrarily set to 1). Data are means $\pm S D$ of three independent experiments. ${ }^{*} P<0.05$ by Student's $t$ test. 
propagation that leads to NK cell effector functions is unclear. To address this, we first compared the amounts of IFN- $\gamma$ secreted by DAP10WT-NKL and DAP10(K84R)NKL cells upon NKG2D engagement. Full activation of the NK cell functional program results from the cooperation of more than one activating receptor (41); therefore, we stimulated NKG2D alone or in combination with stimulation of the activating receptor 2B4. Whereas stimulation with plate-bound anti-NKG2D or anti-2B4 mAb alone failed to stimulate either cell line to secrete IFN- $\gamma$, the coengagement of both NKG2D and 2B4 led to IFN- $\gamma$ production by DAP10WT-NKL cells, but not DAP10(K84R)-NKL cells (Fig. 4A).

We obtained similar results from experiments in which we analyzed the secretion of cytotoxic granules in response to the stimulation of NKL cell transfectants with $\mathrm{FcR}^{+}$ P815 target cells that were coated with antiNKG2D or anti-2B4 mAbs (Fig. 4B), or with $\mathrm{Ba} / \mathrm{F} 3-\mathrm{MICA}$ cells and $\mathrm{Ba} / \mathrm{F} 3-\mathrm{CD} 48$ cells to coengage NKG2D and 2B4 (fig. S2). The percentage of DAP10WT-GFP NKL cells that showed translocation of the cytolytic granule marker CD107a from the inner membrane of granules to the cell surface upon degranulation was substantially greater than that of similarly treated DAP10(K84R)-GFP NKL cells (Fig. 4B). The observed differences were not the result of a general intrinsic functional defect of the DAP10(K84R)-expressing cells, because stimulation of these cells with interleukin-2 (IL-2) or phorbol 12-myristate 13-acetate (PMA) and ionomycin induced similar functional responses in DAP10WT- and DAP10(K84R)expressing cells (Fig. 4B).

To evaluate whether the impairment of NKG2D-mediated effector functions observed in the DAP10(K84R)-GFP NKL cells was a result of a defect in signal propagation, we assessed the phosphorylation events downstream of activation of NKG2D. After NKG2D engagement, Vav1 and the p85 regulatory subunit of PI3K are activated upon their recruitment to the phosphorylated YINM motif of DAP10 (9-11). We found that the extent of phosphorylation of both p85 and Vav1 was similar between DAP10WT-GFP NKL cells and DAP10(K84R)-GFP NKL cells (Fig. 4, C and D), which suggested that early signaling events were not adversely affected by the mutation of DAP10. Among the signaling molecules involved in the activation of NK cell functions, the MAPKs extracellular signal-regulated kinases 1 and $2($ ERK1/2) play a key role in both
A

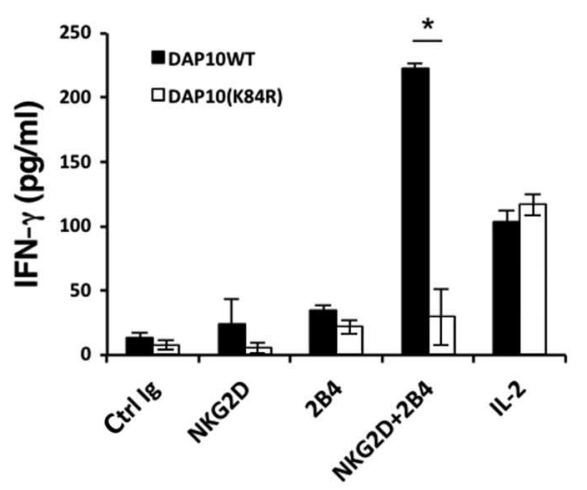

C

DAP10WT DAP10(K84R)

IP: Ctrl Anti-p85 Ctrl Anti-p85

Anti-NKG2D: $--1,5,10^{\prime}--1,5,10^{\prime}$
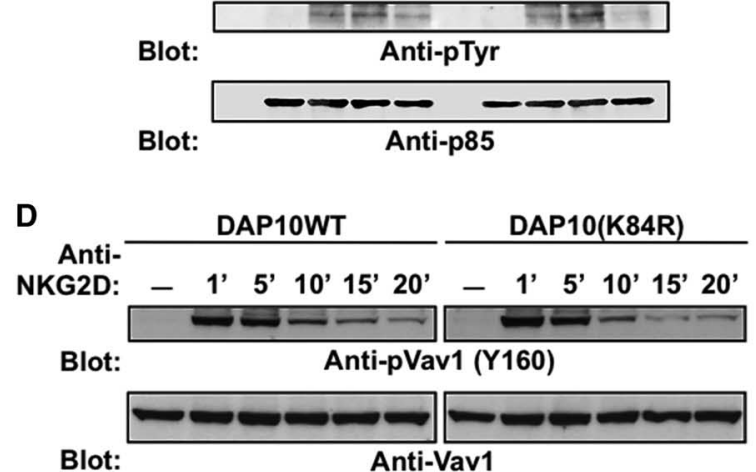

Blot:

Anti-Vav1

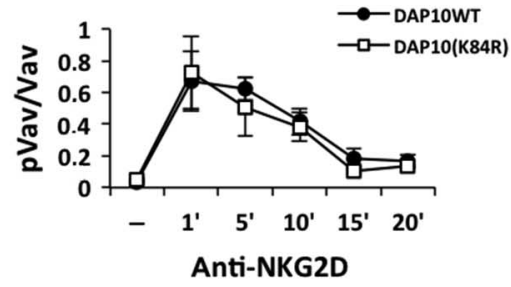

AntiDAP10WT

DAP10(K84R)

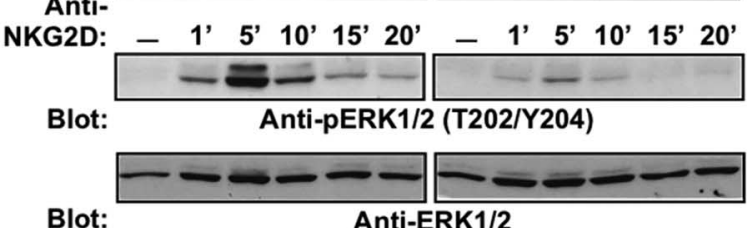

Blot: Anti-ERK1/2

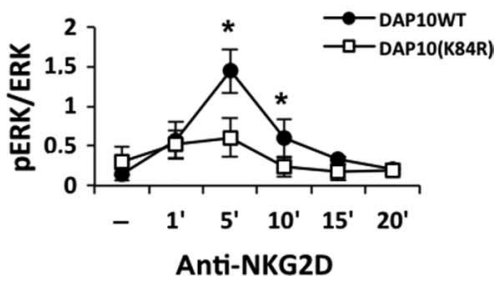

Fig. 4. IFN- $\gamma$ release, cytotoxic granule exocytosis, and ERK1/2 activation are impaired in DAP10(K84R)NKL cells. (A) DAP10WT-GFP and DAP10(K84R)-GFP NKL cells were stimulated overnight with platebound anti-NKG2D and anti-2B4 mAbs alone or in combination, or with IL-2 (1000 U/ml). The amounts of IFN- $\gamma$ released into the cell culture media were measured by enzyme-linked immunosorbent assay (ELISA). Data are means \pm SD of three independent experiments. ${ }^{*} P<0.05$. (B) DAP10WT-GFP and DAP10(K84R)-GFP NKL cells were stimulated for 2 hours with P815 cells that were coated with antiNKG2D or anti-2B4 mAbs alone or in combination, or were treated with PMA ( $50 \mathrm{ng} / \mathrm{ml}$ ) and ionomycin (lono) $(500 \mathrm{ng} / \mathrm{ml})$. Cell surface expression of CD107a was determined by flow cytometric analysis of GFP ${ }^{+}$ cells, and data are expressed as the percentage of $\mathrm{GFP}^{+}$cells that were CD107a ${ }^{+}$. Data are means \pm SD of three independent experiments. ${ }^{*} P<0.05$. (C and D) Left: DAP10WT-GFP and DAP10(K84R)-GFP NKL cells were left unstimulated or were incubated with anti-NKG2D mAb and goat anti-mouse IgG for the indicated times. Cell lysates were then subjected to immunoprecipitation with anti-p85 mAb or with isotype-matched mAb (Ctrl). Immunoprecipitates (C) or total cell lysates (D) were then analyzed by Western blotting with the indicated antibodies. Blots are representative of three independent experiments. Right: The ratios of the abundances of the indicated pairs of total and phosphorylated proteins were determined by densitometric analysis. Data are means \pm SD of three independent experiments. ${ }^{*} P<0.05$ by Student's $t$ test. 
the exocytosis of cytolytic granules and the secretion of IFN- $\gamma(42-45)$. Therefore, we also compared the ERK1/2 activation status in the different NKL cell lines. We found that ERK1/2 phosphorylation in DAP10WTGFP NKL cells was induced at $1 \mathrm{~min}$ after stimulation with anti-NKG2D antibody, peaked at $5 \mathrm{~min}$, and then started to decrease after $10 \mathrm{~min}$ (Fig. 4D, bottom); however, there was a marked reduction in the phosphorylation of ERK1/2 in the DAP10(K84R)-GFP NKL cells, which suggests that DAP10 ubiquitylation was required for the full activation of ERK1/2 in response to NKG2D stimulation.

The ERK pathway targets specific components of the cytoskeleton (46); thus, we investigated whether impaired endocytosis of the NKG2D-DAP10 complex in DAP10(K84R)GFP NKL cells was a consequence of the defect in ERK1/2 activation. We found that NKG2D-DAP10 complexes were internalized to a similar extent in DAP10WT-GFP NKL cells treated with vehicle or the MAPK kinase 1 (MEK1) inhibitor PD098059, which suggests that ERK activation was not involved in receptor endocytosis (fig. S3). Together, these results suggest that DAP10 ubiquitylation is required not only for the lysosomal degradation of NKG2D and DAP10 but also for ERK1/2 activation and NK cell effector functions.

\section{NKG2D endocytosis is required for the activation of ERK1/2}

Because the DAP10(K84R) mutant was much less efficient than its wild-type counterpart in mediating NKG2D internalization and ERK1/2 phosphorylation, we postulated that the endocytosis of the NKG2D-DAP10 complex might be required for ERK activation. To determine whether the inhibition of NKG2D internalization affected signal propagation and NK cell functional response, we treated primary cultured human NK cells with dynasore, a selective inhibitor of the guanosine triphosphatase (GTPase) dynamin, which blocks both clathrin-dependent and clathrin-independent endocytosis (47). By microscopic analysis, we observed that the inhibitor efficiently blocked receptor endocytosis induced by crosslinking with the anti-NKG2D mAb (Fig. 5A). Moreover, we found that dynasore inhibited the release of $\mathrm{CD} 107 \mathrm{a}^{+}$cytolytic granules induced by the engagement of NKG2D or 2B4 either alone or in combination (Fig. 5B). Similar results were obtained upon stimulation of primary human NK cells with $\mathrm{Ba} / \mathrm{F} 3-\mathrm{MICA}$ target cells (fig. S4). Dynasore-treated primary
A

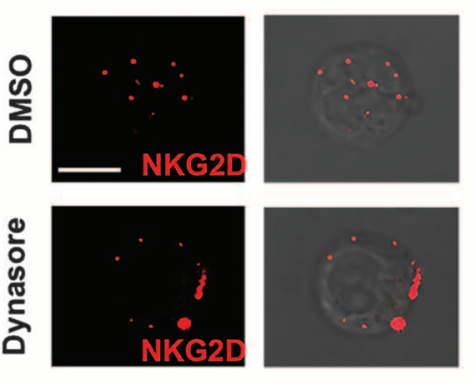

B

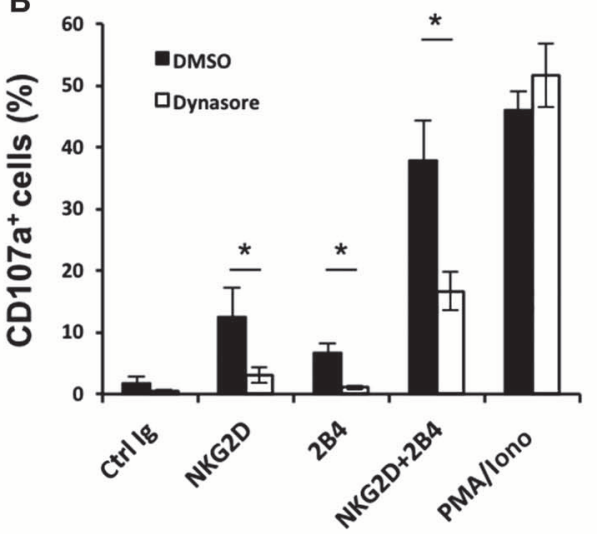

C

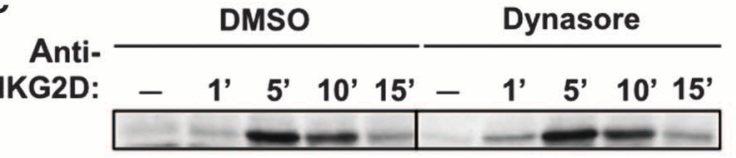

Blot:

Anti-pAkt (S473)

Blot:

Anti-Akt

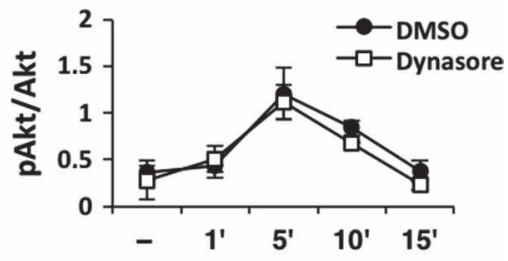

Anti-NKG2D

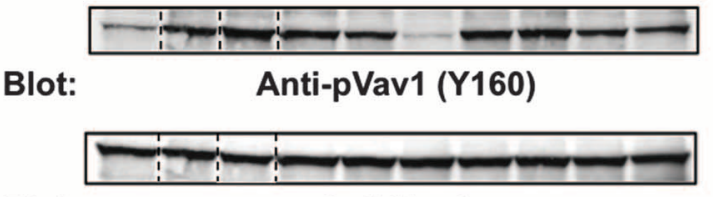

Blot:

Anti-Vav1
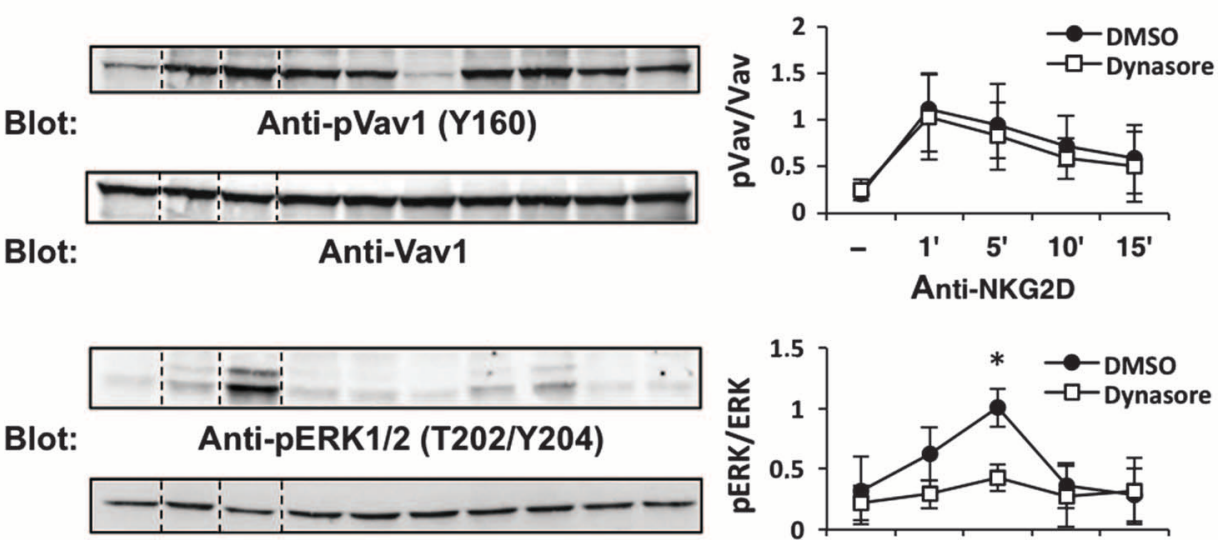

Blot:

Anti-ERK1/2

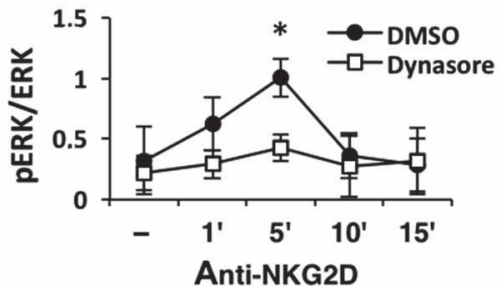

Fig. 5. Dynasore impairs cytotoxic granule exocytosis and ERK $1 / 2$ activation in primary cultured NK cells. (A) Primary cultured human NK cells were preincubated for 30 min in RPMl containing $100 \mu \mathrm{M}$ dynasore or dimethyl sulfoxide (DMSO) at $37^{\circ} \mathrm{C}$. Cells were then stimulated and analyzed as described for Fig. 2C. Scale bar, $5 \mu \mathrm{m}$. Images are representative of four independent experiments. (B) Primary cultured human NK cells were treated with $100 \mu \mathrm{M}$ dynasore or DMSO for 30 min and then were incubated for 2 hours with P815 cells that were coated with anti-NKG2D or anti-2B4 mAbs alone or in combination, as indicated, or were treated with PMA and ionomycin. Cell surface expression of CD107a was determined by flow cytometric analysis of $\mathrm{CD}_{56}{ }^{+} \mathrm{CD} 3^{-}$cells, and data are expressed as the percentage of $\mathrm{CD} 56^{+} \mathrm{CD}^{-}$cells that

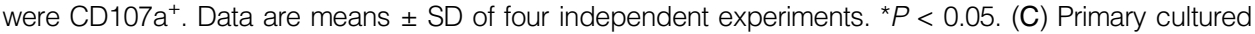
human NK cells were treated with $100 \mu \mathrm{M}$ dynasore or DMSO for $30 \mathrm{~min}$ and then were left unstimulated or were incubated with anti-NKG2D mAb and goat anti-mouse IgG for the indicated times. Left: Cell lysates were analyzed by Western blotting with the indicated antibodies. The black vertical lines indicate noncontiguous blots, whereas dashed vertical lines indicate repositioned lanes from the same blot. Right: The ratios of the abundances of the indicated pairs of total and phosphorylated proteins were determined by densitometric analysis. Data are means \pm SD of three independent experiments. ${ }^{*} P<0.05$ by Student's $t$ test. 
NK cells did not show general defects in granule exocytosis because they responded to PMA and ionomycin, a nonspecific stimulatory signal (Fig. 5B).

Treatment of primary NK cells with dynasore had no effect on the extent of phosphorylation of either Vav1 or Akt in response to stimulation with an anti-NKG2D antibody (Fig. 5C); however, primary NK cells treated with the inhibitor showed a defect in ERK1/2 phosphorylation (Fig. 5C), which was comparable to the defect observed in DAP10(R84R)-GFP NKL cells (Fig. 4D). We then used a small interfering RNA (siRNA)-based approach combined with confocal microscopy and biochemical analysis. Transfection of parental NKL cells with dynamin 2-specific siRNA led to about a $60 \%$ reduction in the abundance of dynamin 2 compared to that in cells transfected with nontargeting control siRNA (Fig. 6A). Consistent with the results obtained from the experiments with dynasore, knockdown of dynamin 2 reduced the extent of NKG2D endocytosis (Fig. 6B) and ERK1/2 phosphorylation (Fig. 6C) upon receptor stimulation. Together, our results indicate that ERK1/2 activation and NK cell effector functions depend on the endocytosis of NKG2D, which suggests that the distribution of activated receptor complexes in endosomal compartments enables signal propagation.

\section{Phosphorylated ERK1/2 and internalized NKG2D-DAP10 complexes colocalize with early endosomes upon receptor engagement}

Several studies have demonstrated that the activation of the ERK signaling pathway can take place in endosomes (29-34). To study whether phosphorylated ERK1/2 (pERK) and internalized NKG2D-DAP10 complexes accumulated in early endosomal compartments, we performed double staining of pERK and the endosomal marker EEA1 (early endosome antigen 1) in DAP10WT-GFP NKL cells upon stimulation with anti-NKG2D mAb, and we analyzed the colocalization of DAP10-GFP with EEA1-positive endosomes. The signal corresponding to pERK increased upon NKG2D stimulation; during the first 5 min of stimulation, we observed only a slight increase in pERK immunostaining, which reached a maximum at $10 \mathrm{~min}$ and declined at $15 \mathrm{~min}$ (fig. S5). Thus, colocalization between active ERK1/2 and EEA1-positive endosomes was evaluated at these latter time points. Colocalization was transient, reaching a maximum at $10 \mathrm{~min}$ (Fig. 7, $\mathrm{A}$ and $\mathrm{B}$, left), and decreasing at $15 \mathrm{~min}$ (Fig. 7B, left). In addition, we found that the DAP10-GFP fusion proteins also colocalized with EEA1-containing compartments with overlapping kinetics (Fig. 7, A and $\mathrm{B}$, left). Furthermore, the colocalization indexes for DAP10-GFP/EEA1 and $\mathrm{pERK} / \mathrm{EEA} 1$ that were calculated for each cell at $10 \mathrm{~min}$ of stimulation showed a positive correlation $(R=0.75 ; P<0.0001)$ (Fig. 7B, right). These results indicate that internalized NKG2D-DAP10 complexes and pERK $1 / 2$ transiently localize in early endosomes, which suggests that receptor internalization may be required for the recruitment of ERK1/2 into this compartment and for its activation.

\section{DISCUSSION}

Much evidence suggests that upon ligand binding, NKG2D-DAP10 complexes are internalized from the surface of NK cells and CD8 ${ }^{+} \mathrm{T}$ cells and are subjected to subsequent degradation in lysosomes $(17,26,48)$. However, to date, little is known about the molecular mechanisms that control NKG2D-DAP10 endocytosis or about its possible connection with downstream signaling. Here, we found that upon NKG2D engagement on human NK cells, DAP10 was subjected to ubiquitylation (Fig. 1) and that this modification was required for endocytosis of the NKG2D-DAP10 complex (Fig. 2). The involvement of the cytoplasmic domain of DAP10 in its internalization was previously reported in several studies, and tyrosine phosphorylation in the YINM motif is indispensable for endocytosis
A

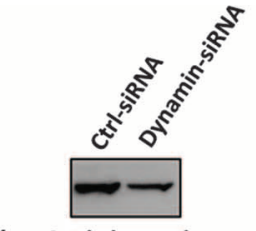

Blot: Anti-dynamin

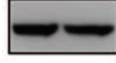

Blot: Anti-ZAP70
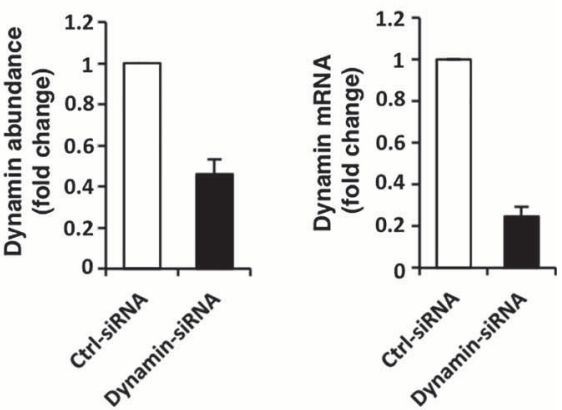

B
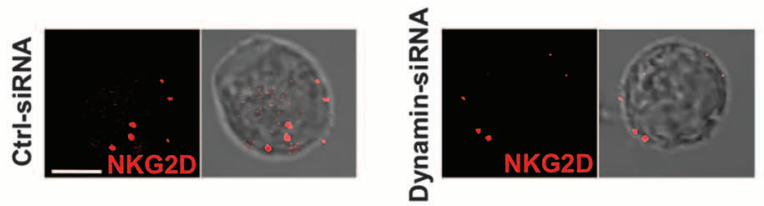

C
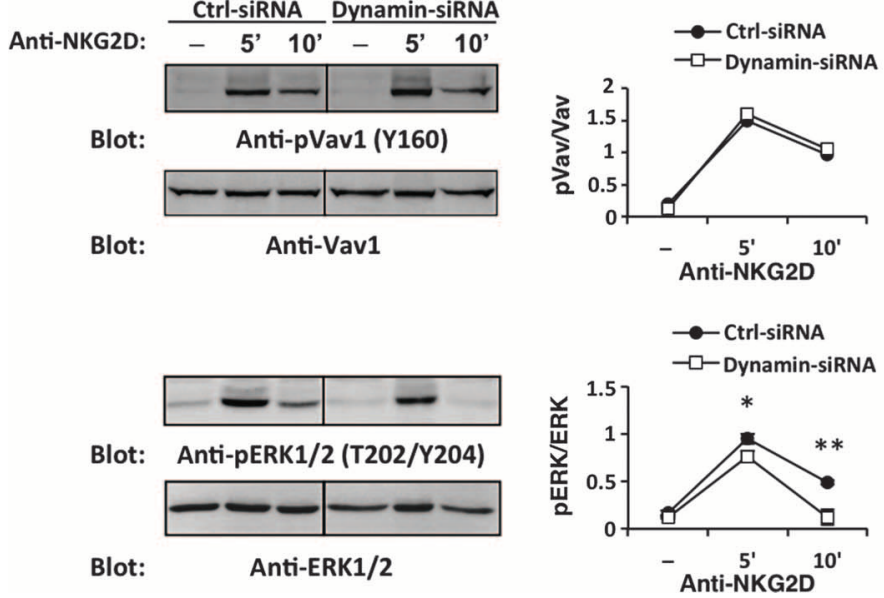

Fig. 6. Knockdown of dynamin 2 impairs ERK1/2 activation in NKL cells. (A) NKL cells were transfected with dynamin 2-specific siRNA or with control siRNA. Left: Forty-eight hours later, whole-cell lysates were analyzed by Western blotting with the indicated antibodies. Middle: The amounts of dynamin protein, normalized to that of ZAP70, were determined by densitometric analysis and are relative to that in unstimulated cells (which was arbitrarily set to 1). Data are means \pm SD of three independent experiments. Right: The amounts of dynamin2 mRNA, normalized to that of GAPDH mRNA, were determined by quantitative reverse transcription polymerase chain reaction (qRT-PCR) analysis and are expressed as the fold change relative to that in cells transfected with control siRNA. Data are means \pm SD of three independent experiments. (B) NKL cells transfected with the indicated siRNAs were stimulated for $30 \mathrm{~min}$ at $37^{\circ} \mathrm{C}$ and analyzed as described for Fig. 2C. Scale bar, $5 \mu \mathrm{m}$. (C) NKL cells transfected with the indicated siRNAs were left unstimulated or were incubated at $37^{\circ} \mathrm{C}$ with anti-NKG2D and goat anti-mouse IgG for the indicated times. Left: Wholecell lysates were analyzed by Western blotting with the indicated antibodies. The black vertical lines indicate noncontiguous blots. Right: The ratios of the abundances of the indicated pairs of total and phosphorylated proteins were determined by densitometric analysis. Data are means \pm SD of three independent experiments. ${ }^{\star \star} P<0.01,{ }^{\star} P<0.05$ by Student's $t$ test. 
A
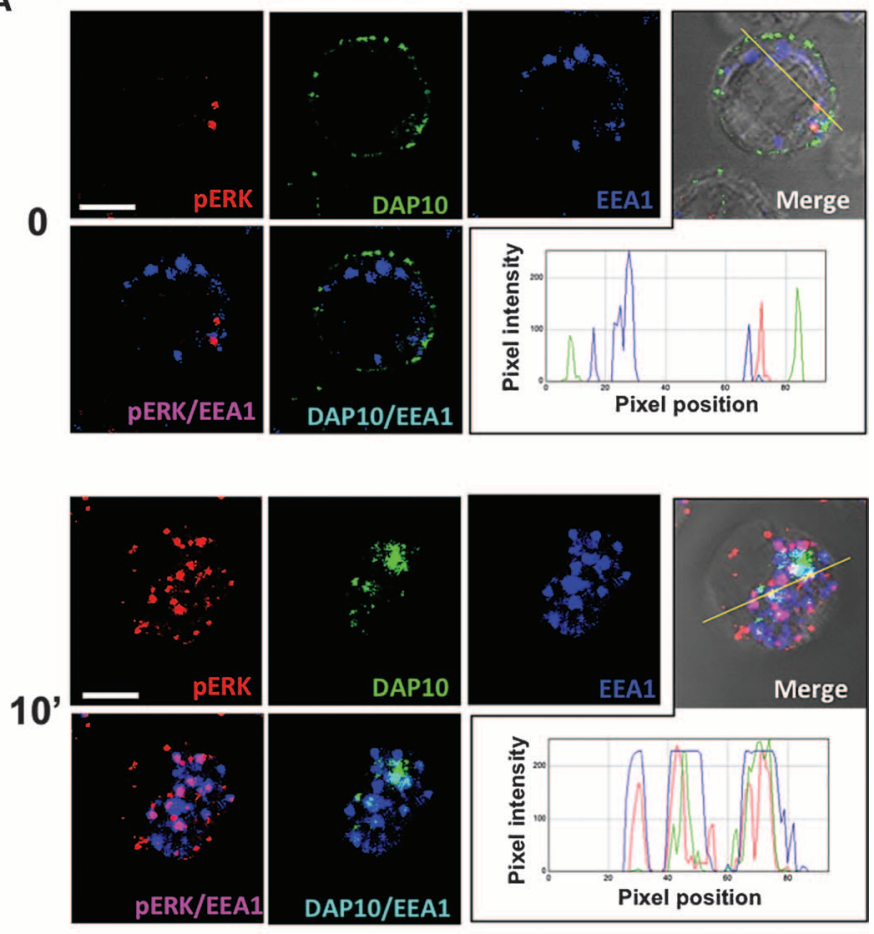

B
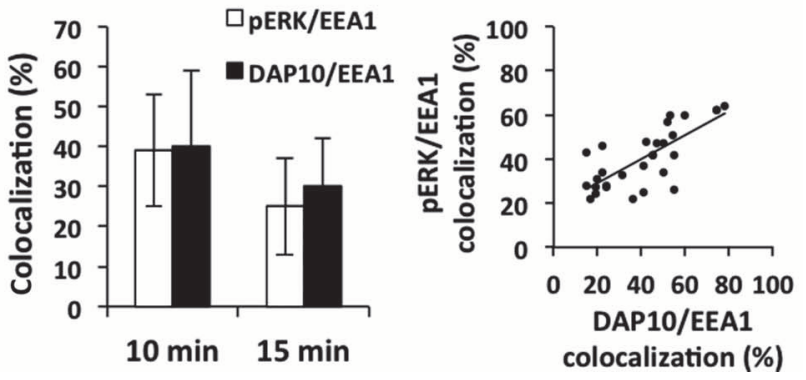

Fig. 7. Internalized DAP10 and pERK1/2 colocalize with EEA1-positive endosomes in NKL cells. (A) DAP10WT-GFP NKL cells were incubated with anti-NKG2D mAb and then were left untreated on ice $(0)$ or were incubated with goat anti-mouse antibody for $10 \mathrm{~min}$ at $37^{\circ} \mathrm{C}$. The cells were then plated on poly-L-lysine-coated coverslips, fixed, permeabilized, and incubated with anti-pERK1/2 antibody followed by an Alexa Fluor 594-conjugated goat anti-rabbit antibody (red), as well as with Pacific Blue-conjugated antiEEA1 rabbit antibody (blue). The coverslips were then washed, mounted, and analyzed by confocal microscopy. Representative images of single cells are shown as maximum intensity projections (six $Z$ sections with $0.46-\mu \mathrm{m}$ spacing). An overlay of the three-color merged image and the bright-field image is also shown, and the fluorescence histograms of each channel in the region of interest (ROI) (yellow line) are plotted. Scale bar, $5 \mu \mathrm{m}$. (B) Left: Percentage of colocalization of pERK $1 / 2$ with EEA1 and of DAP10-GFP with EEA1 at the indicated times. Data are means \pm SD of colocalization indexes from three independent experiments ( $n=29$ cells) calculated with FluoView software. Right: Scatter graph with regression line to show the correlation between DAP10-EEA1 and pERK-EEA1 colocalization indexes calculated in single cells after 10 min of stimulation $(R=0.75$; $P<0.0001)$. Each dot represents a single cell ( $n=29$ cells).
$(48,49)$. Here, we demonstrated that in addition to phosphorylation of DAP10, its ubiquitylation was also required for the endocytosis of engaged receptor complexes. We further found that DAP10 ubiquitylation was essential for degradation of the NKG2D-DAP10 complex (Fig. 3), which is consistent with a study that demonstrated that a chimeric protein in which ubiquitin was fused to the C terminus of mouse DAP10 targeted DAP10ubiquitin and NKG2D for constitutive internalization and degradation (50).

The major finding of our study is that the ubiquitin-dependent endocytosis of the engaged NKG2D-DAP10 complex was required for efficient activation of NK cell effector functions, in terms of both cytolytic granule exocytosis and IFN- $\gamma$ release (Fig. 4, A and B). Experiments with primary NK cells in which endocytosis was inhibited showed that cytolytic granule secretion induced by 2B4 engagement alone was substantially impaired (Fig. 5B). Together, these results suggest that signaling from endosomal compartments is required to enable full NK cell activation. With respect to signaling, we found that receptor-proximal phosphorylation events did not require receptor endocytosis (Figs. 4, C and D, 5C, and 6C). However, we found that the phosphorylation of ERK1/2 was impaired in NK cells in which endocytosis was inhibited (Figs. 4D, 5C, and 6C). Moreover, pERK transiently associated with endosomal compartments in which internalized DAP10-GFP fusion proteins were also present (Fig. 7).

Together, our findings led us to propose a model (fig. S6) in which the ubiquitin-dependent internalization of NKG2D-DAP10 and its trafficking along endosomes are required for the activation of ERK1/2 in endosomal compartments before the receptors reach lysosomes and undergo degradation. We propose that $\mathrm{pERK}$ could then detach from endosomes or translocate to the nucleus to reach its targets, thus enabling signal propagation and the functional response. With regard to other immune receptors, there is little evidence in support of a role of endosomal signaling. In the case of the B cell receptor (BCR), intracellular trafficking of the receptor is important to control the correct extent of activation of the MAPK and Akt signaling pathways and their downstream effects (35), and components that activate c-Jun N-terminal kinase (JNK) are recruited in proximity to active BCR in endosomes (36). Endosomes may also participate in $\mathrm{T}$ cell signaling; upon TCR stimulation, there is an accumulation of phosphorylated $\mathrm{CD} 3 \zeta$ in endosomes (37), and the phosphorylated adaptor protein LAT (linker of activated T cells) can be found in intracellular vesicles (38). Moreover, TCR internalization ensures the appropriate signaling strength that is required to promote the proliferation of mouse $\mathrm{T}$ cells in vivo (39).

Different scenarios are exemplified by Toll-like receptor 4 (TLR4), which activates diverse signaling pathways based on its location (at the cell surface versus in endosomes) (51), and by killer cell immunoglobulin-like receptor, two domains, long cytoplasmic tail, 4 (KIR2DL4), an activating receptor found on NK cells and some $\mathrm{T}$ cell subsets, which accumulates in early endosomes to initiate a proinflammatory cascade $(52,53)$. Endosomal signaling has been extensively investigated in the cases of the RTK and GPCR families, in which it controls processes such as proliferation, differentiation, and inflammation (28). The rate of internalization of such receptors is substantially higher than the rate of their lysosomal targeting and degradation. As a consequence, there is a prolonged residence of these signaling receptors in endosomes after ligand-induced endocytosis, and signaling is sustained (54-57). With respect to NKG2D-DAP10, we found that receptor internalization was rapidly followed by lysosomal degradation, suggesting that the contribution of endosomal signaling would serve to guarantee signal propagation, rather than to sustain it. Indeed, in cytotoxic lymphocytes, the exocytosis of cytolytic granules is a rapid process, which is highly controlled and directed to the appropriate target.

In the context of an NK cell, for which the functional response is the result of a delicate balance of signals from activating and inhibitory 
receptors (14), compartmentalization of transducing components between the cell surface and endosomal membranes could serve to better control the outcome of receptor engagement. Moreover, endosomes may represent platforms for the integration of synergistic signals triggered by different engaged receptors, thus adding an extensive and complex level of functional regulation. In conclusion, we demonstrated that the ubiquitindependent endocytosis of an immune receptor served to regulate effector functions, and we provided evidence that a cooperative interaction between NKG2D signaling and endocytosis is required to enable NKG2D-mediated NK cell functions.

\section{MATERIALS AND METHODS}

\section{Cell culture}

The human NK cell line NKL was cultured in RPMI 1640 medium supplemented with $10 \%$ fetal calf serum (FCS) and recombinant human IL-2 ( $200 \mathrm{U} / \mathrm{ml}$; R\&D Systems). All biochemical studies and IFN- $\gamma$ release assays were performed with NKL cells after 24 hours of IL-2 deprivation. Human NK cell cultures were obtained by coculturing peripheral blood mononuclear cells with irradiated RPMI 8866 cells for 10 days at $37^{\circ} \mathrm{C}$ in a humidified $5 \% \mathrm{CO}_{2}$ atmosphere. On day 10 , the cell population was routinely 80 to $95 \% \mathrm{CD}^{2} 6^{+}, \mathrm{CD} 16^{+}$, and $\mathrm{CD}^{-}$as assessed by immunofluorescence and flow cytometric analysis. Experiments were then performed on NK cell populations that were $>90 \%$ pure. The $\mathrm{Ba} / \mathrm{F} 3-\mathrm{MICA}$ and $\mathrm{Ba} /$ F3-CD48 cell lines were provided by L. L. Lanier (University of San Francisco) and were maintained in RPMI medium supplemented with $10 \%$ FCS. The P815 murine mastocytoma FcR $\gamma^{+}$cell line was grown in RPMI medium supplemented with $10 \%$ FCS.

\section{NK cell stimulation}

NKL cell stimulation (Fig. 1A) was performed with fixed Ba/F3-MICA target cells. Briefly, target cells were treated with $1 \%$ PFA for 30 min at room temperature, washed extensively in cold phosphate-buffered saline (PBS), suspended in RPMI medium, and then added to the NKL cells. The stimulation was stopped by washing with cold PBS, and lysis buffer was added to both the effector and fixed target cells, whose lysis was prevented by the pretreatment with $1 \%$ PFA, as previously reported (45). For stimulation with anti-NKG2D antibody, NKL cells or primary cultured NK cells were incubated with anti-NKG2D mAb (clone 149810, R\&D Systems) for $30 \mathrm{~min}$ on ice. Goat anti-mouse antibody (Jackson ImmunoResearch) was added and incubated at $37^{\circ} \mathrm{C}$ for the times indicated in the figure legends. To visualize NKG2D by microscopic analysis, receptor engagement was achieved with an Alexa Fluor 350-conjugated goat anti-mouse IgG1 (Invitrogen). Pervanadate was freshly prepared by mixing $50 \mathrm{mM}$ vanadate and $50 \mathrm{mM} \mathrm{H}_{2} \mathrm{O}_{2}$ in PBS to give a $25 \mathrm{mM}$ solution of pervanadate, which was then diluted in cell culture medium to give a final concentration of $1 \mathrm{mM}$. To inhibit endocytosis, primary cultured NK cells were pretreated at $37^{\circ} \mathrm{C}$ for $30 \mathrm{~min}$ with $100 \mu \mathrm{M}$ dynasore (Sigma-Aldrich). To inhibit ERK1/2 activation, NKL cells were incubated at $37^{\circ} \mathrm{C}$ for 1 hour with the MEK1 inhibitor PD98059 (Millipore). Stimulation was conducted in the presence of the respective inhibitors. Cell viability was $>90 \%$ before stimulation.

\section{Plasmids, transfections, and siRNAs}

The complementary DNA (cDNA) encoding full-length human Dap10 was subcloned from the total cDNA of the NKL cell line by RT-PCR assay with gene-specific primers (forward: 5'-gagagatcttccaccatgatccatctgg-3'; reverse: $5^{\prime}$-gtggatccetgcctggcatgttgatgt- $\left.3^{\prime}\right)$, and the fragment was inserted into the pEGFP-N1 vector (Clontech Laboratories) at the Bgl II and
Bam H1 sites to generate a construct encoding GFP fused to the C terminus of DAP10. The DAP10(K84R)-GFP mutant was prepared by PCR (QuikChange Site-Directed Mutagenesis Kit, Stratagene) using the pEGFPN1-DAP10-GFP plasmid as template and the following primers: forward, $5^{\prime}$-cgcccaagatggcagagtctacatcaacatgcc- $3^{\prime}$; reverse, $5^{\prime}$-ggcatgttgatgtagactctgccatcttgggeg- $3^{\prime}$. The integrity of the plasmid constructs was verified by DNA sequence analysis. The plasmids were digested with Ase I, and NKL cells were transfected with $2.5 \mu \mathrm{g}$ of linearized plasmids with the Amaxa 4D-Nucleofector System, SF solution, program EO-100 (Lonza Group Ltd.). Transfected cells were grown under selection with G418 $(1 \mathrm{mg} / \mathrm{ml})$, and the bulk stable cells were sorted on the basis of GFP abundance with a FACSAria sorter (BD Biosciences) equipped with a 488-nm laser and FACSDiva software (version 6.1.3, BD Biosciences). Briefly, cells first gated by forward and side scatter (FSC-A and SSC-A) were then detected in the green fluorescence channel for comparable GFP abundance. Dynamin 2specific siRNA (5'-AAGGACCAGGCAGAAAACGAG-3') and a control nontargeting siRNA (5'-UAAGGCUAUGAAGAGAUACUU-3') were purchased from Eurofins MWG Operon. Specific protein knockdown was achieved by transfecting NKL cells with siRNA duplexes by electroporation with an Amaxa 4D-Nucleofector System (Lonza). Briefly, $2 \times 10^{6}$ cells were resuspended in $100 \mu \mathrm{l}$ of Amaxa SF solution, mixed with $600 \mathrm{pmol}$ of siRNA, and transfected with program CM-137. Forty-eight hours after transfection, the knockdown efficiency was evaluated by Western blotting and qRT-PCR analyses.

\section{RNA isolation and qRT-PCR analysis}

Total RNA isolation and reverse transcription were performed as previously described (58). Real-time PCR analysis was performed with TaqMan assays and the ABI Prism 7900 Sequence Detection system (Applied Biosystems). The cDNAs were amplified in triplicate with primers specific for dynamin 2 (Hs00974698_ml) conjugated with the fluorochrome FAM (Applied Biosystems). The abundance of dynamin 2 mRNA was measured as previously described (58), and all samples were normalized to the abundance of GAPDH mRNA.

\section{Immunoprecipitation and Western blotting analysis}

Cells were lysed in a buffer ( $\mathrm{pH} 7.5$ ) containing 1\% Triton X-100, $50 \mathrm{mM}$ tris- $\mathrm{HCl}$ (pH 7.5), $150 \mathrm{mM} \mathrm{NaCl}, 2.5$ mM EGTA (pH 8), 2.5 mM EDTA (pH 8), $1.5 \mathrm{mM} \mathrm{MgCl}, 1 \mathrm{mM}$ phenylmethylsulfonyl fluoride, $1 \mathrm{mM}$ $\mathrm{Na}_{3} \mathrm{VO}_{4}, 5 \mathrm{mM} \mathrm{NaF}$ (pH 8), $5 \mathrm{mM} N$-ethylmaleimide, aprotinin $(10 \mu \mathrm{g} / \mathrm{ml})$, and leupeptin $(5 \mu \mathrm{g} / \mathrm{ml})$. Immunoprecipitations were performed by binding the appropriate antibodies to protein A-Sepharose beads (Amersham Pharmacia) or protein G-Sepharose beads (Sigma-Aldrich), and then incubating them with equal amounts of protein from the cell lysates of each sample. The immunoprecipitates were washed five times with lysis buffer, and bound proteins were eluted with Laemmli buffer containing 5\% 2-mercaptoethanol. Immunoprecipitates or total cell lysates were resolved by SDS-PAGE and transferred to nitrocellulose filters. After undergoing blocking of nonspecific reactivity, filters were incubated with specific primary and secondary antibodies diluted in TBS-T [ $20 \mathrm{mM}$ tris- $\mathrm{HCl}(\mathrm{pH} 7.8)$, $150 \mathrm{mM} \mathrm{NaCl}, 0.05 \%$ Tween 20]. After extensive washing, the immunoreactive bands were detected with an enhanced chemiluminescence detection kit (Amersham Pharmacia). The following antibodies were used for immunoprecipitation and Western blotting: anti-GFP (Invitrogen); antiNKG2D (clone 3.1.1.1), anti-ZAP70, anti-phosphotyrosine, anti-Vav1, and anti-p85 (all from Millipore); anti-Akt, anti-pAkt (S473), anti-ERK1/2, and anti-pERK1/2(T202/Y204) (all from Cell Signaling Technology); antiubiquitin (clone FK2, Enzo Life Sciences); anti-dynamin 2 (5E4C2F3, Santa Cruz Biotechnology); and anti-pVav (Y160) (Life Technologies). Densitometric analysis was performed with ImageJ software. 


\section{In vitro ubiquitylation assay}

DAP10-GFP was immunoprecipitated from unstimulated DAP10WT-GFP NKL cells and used as source of substrate for in vitro ubiquitylation assays. The immunocomplexes were washed five times with lysis buffer and once with $1 \times$ ubiquitylation buffer [50 mM tris ( $\mathrm{pH} 7.5), 0.5 \mathrm{mM} \mathrm{MgCl}_{2}$, $0.1 \mathrm{mM}$ adenosine triphosphate, $0.1 \mathrm{mM}$ dithiothreitol, $1 \mathrm{mM}$ creatine phosphate] and incubated in $40 \mu \mathrm{l}$ of the same buffer supplemented with $70 \%(\mathrm{v} / \mathrm{v})$ RRLs, creatine phosphokinase $(10 \mathrm{U})$, and $10 \mu \mathrm{g}$ of ubiquitin for 2 hours at $30^{\circ} \mathrm{C}(23)$. After in vitro ubiquitylation, all samples were washed three times with lysis buffer, eluted with SDS sample buffer, resolved by SDS-PAGE, and transferred electrophoretically to nitrocellulose filters.

\section{Immunofluorescence and microscopic analysis}

NKL cells or primary cultured NK cells were stimulated with antiNKG2D mAb as described earlier. After stimulation, the cells were gently resuspended, plated on poly-L-lysine-coated multichamber glass plates, and fixed with 4\% PFA. After extensive washing, the coverslips were mounted with SlowFade Gold reagent (Life Technologies) and acquired at room temperature with an ApoTome Observer Z.1 microscope with a $63 \times / 1.4$ NA (numerical aperture) Plan-Neofluar oil immersion objective (Carl Zeiss), as previously described $(59,60)$. When colocalization analysis was required, cells were permeabilized with $0.1 \%$ Triton X-100 for 5 min to stain intracellular antigens, and were incubated with the following antibodies diluted in blocking buffer ( $0.01 \%$ Triton X-100, $1 \%$ FCS): antipERK1/2 (Cell Signaling Technologies) followed by an Alexa Fluor 594 conjugated goat anti-rabbit antibody (Invitrogen); anti-EEA1 (Santa Cruz Biotechnology), which was conjugated with Pacific Blue with an Antibody Labeling Kit (Life Technologies). High-resolution images $(640 \times$ 640 pixel, $10 \mu \mathrm{s} /$ pixel) were acquired with a FV1200 MPE laser-scanning confocal microscope (Olympus) with a $60 \times / 1.35$ NA UPlanSAPO oil immersion objective. Sequential acquisition was used to avoid crosstalk between different fluorophores. Quantification of colocalization was performed with FluoView 4.2 software, considering colocalization indexes between two channels on single cells (ROI) after background correction. Images were processed with ImageJ software.

\section{NK cell functional assays}

Degranulation of NK cells was determined by detection of the cell surface expression of CD107a, as previously described (41), with some modifications. Briefly, P815 cells $\left(2 \times 10^{5}\right)$ were incubated for $15 \mathrm{~min}$ at room temperature with $2 \mu \mathrm{g}$ of the following mAbs: anti-NKG2D (R\&D Systems), anti-2B4 (Beckman Coulter), or both. NK cells $\left(1 \times 10^{5}\right)$ were then mixed with $\mathrm{P} 815, \mathrm{Ba} / \mathrm{F} 3-\mathrm{MICA}$, or $\mathrm{Ba} / \mathrm{F} 3-\mathrm{CD} 48$ cells, and the cells were centrifuged for $1 \mathrm{~min}$ at $100 \mathrm{~g}$ and incubated for 2 hours at $37^{\circ} \mathrm{C}$. Thereafter, cells were washed with PBS/5 mM EDTA, fixed with $2 \%$ PFA, and stained with allophycocyanin (APC)-conjugated anti-CD107a mAb or with isotope control (BD Biosciences) and, when primary NK cells were used, with peridinin chlorophyll protein (PerCP)-conjugated anti-CD3 antibody and phycoerythrin (PE)-conjugated anti-CD56 mAbs (BD Biosciences). Flow cytometric analysis was performed with a BD FACSCanto II flow cytometer equipped with 488- and 633-nm lasers and with DIVA software (BD Biosciences). NKL cells were gated on the basis of GFP abundance $\left(\mathrm{GFP}^{+}\right.$cells), whereas primary NK cells were gated as $\mathrm{CD}^{-}$and $\mathrm{CD}^{+} 6^{+}$ cells. To measure IFN- $\gamma$ release by ELISA, NKL cells were stimulated with IL-2 $(1000 \mathrm{U} / \mathrm{ml})$ or with plate-bound mAbs in flat-bottomed 96-well plates in which the wells were coated with goat anti-mouse immunoglobulin $\mathrm{G}(\mathrm{IgG})\left(2 \mu \mathrm{g}\right.$ per well in PBS) overnight at $4^{\circ} \mathrm{C}$ and then for 1 hour at $37^{\circ} \mathrm{C}$ with $\mathrm{mAbs}(1 \mu \mathrm{g}$ per well in PBS). After washing, NKL cells $\left(2 \times 10^{5}\right.$ cells per well in RPMI medium supplemented with $10 \%$ FCS) were added onto the plates and were left overnight at $37^{\circ} \mathrm{C}$ before cell culture medium was collected. IFN- $\gamma$ concentrations were measured with the human IFN- $\gamma$ ELISA kit (Thermo Scientific).

\section{Statistical analysis}

For normally distributed data, statistical significance of differences between two groups was determined by performing two-tailed, paired Student's $t$ tests. Data shown in graphs are means \pm SD of at least three independent experiments. Linear regression analyses were performed to determine correlations between normally distributed data variables (colocalization indexes). Correlations are presented by expressing the Pearson's correlation coefficient $R$ together with the $P$ value for related statistical significance.

\section{SUPPLEMENTARY MATERIALS}

www.sciencesignaling.org/cgi/content/full/8/400/ra108/DC1

Fig. S1. Characterization of the DAP10WT-GFP and DAP10(K84R)-GFP NKL cell lines. Fig. S2. Cytotoxic granule exocytosis induced upon coengagement of NKG2D and 2B4 is inhibited in DAP10(K84R)-GFP NKL cells.

Fig. S3. PD098059 does not inhibit DAP10 internalization in DAP10WT-GFP NKL cells. Fig. S4. Dynasore impairs cytotoxic granule release by cultured primary NK cells in response to stimulation with $\mathrm{Ba} / \mathrm{F} 3-\mathrm{MICA}$ cells.

Fig. S5. Analysis of the kinetics of ERK1/2 phosphorylation by confocal microscopy. Fig. S6. Proposed model of the molecular mechanisms underlying NKG2D-DAP10 endocytosis and signaling in response to receptor engagement.

\section{REFERENCES AND NOTES}

1. S. González, V. Groh, T. Spies, Immunobiology of human NKG2D and its ligands. Curr. Top. Microbiol. Immunol. 298, 121-138 (2006).

2. E. Ullrich, J. Koch, A. Cerwenka, A. Steinle, New prospects on the NKG2D/NKG2DL system for oncology. Oncoimmunology 2, e26097 (2013).

3. D. H. Raulet, S. Gasser, B. G. Gowen, W. Deng, H. Jung, Regulation of ligands for the NKG2D activating receptor. Annu. Rev. Immunol. 31, 413-441 (2013).

4. M. Champsaur, L. L. Lanier, Effect of NKG2D ligand expression on host immune responses. Immunol. Rev. 235, 267-285 (2010)

5. M. J. Smyth, J. Swann, E. Cretney, N. Zerafa, W. M. Yokoyama, Y. Hayakawa, NKG2D function protects the host from tumor initiation. J. Exp. Med. 202, 583-588 (2005).

6. N. Guerra, Y. X. Tan, N. T. Joncker, A. Choy, F. Gallardo, N. Xiong, S. Knoblaugh, D. Cado, N. M. Greenberg, N. R. Greenberg, D. H. Raulet, NKG2D-deficient mice are defective in tumor surveillance in models of spontaneous malignancy. Immunity 28, 571-580 (2008).

7. D. Garrity, M. E. Call, J. Feng, K. W. Wucherpfennig, The activating NKG2D receptor assembles in the membrane with two signaling dimers into a hexameric structure. Proc. Natl. Acad. Sci. U.S.A. 102, 7641-7646 (2005).

8. S. Bauer, V. Groh, J. Wu, A. Steinle, J. H. Phillips, L. L. Lanier, T. Spies, Activation of NK cells and T cells by NKG2D, a receptor for stress-inducible MICA. Science 285, 727-729 (1999).

9. D. D. Billadeau, J. L. Upshaw, R. A. Schoon, C. J. Dick, P. J. Leibson, NKG2D-DAP10 triggers human NK cell-mediated killing via a Syk-independent regulatory pathway. Nat. Immunol. 4, 557-564 (2003).

10. J. L. Upshaw, L. N. Arneson, R. A. Schoon, C. J. Dick, D. D. Billadeau, P. J. Leibson, NKG2D-mediated signaling requires a DAP10-bound Grb2-Vav1 intermediate and phosphatidylinositol-3-kinase in human natural killer cells. Nat. Immunol. 7, 524-532 (2006).

11. J. Wu, Y. Song, A. B. H. Bakker, S. Bauer, T. Spies, L. L. Lanier, J. H. Phillips, An activating immunoreceptor complex formed by NKG2D and DAP10. Science 285, 730-732 (1999).

12. C. Chang, J. Dietrich, A. G. Harpur, J. A. Lindquist, A. Haude, Y. W. Loke, A. King, M. Colonna, J. Trowsdale, M. J. Wilson, Cutting edge: KAP10, a novel transmembrane adapter protein genetically linked to DAP12 but with unique signaling properties. J. Immunol. 163, 4651-4654 (1999).

13. L. L. Lanier, NK cell recognition. Annu. Rev. Immunol. 23, 225-274 (2005).

14. E. O. Long, H. S. Kim, D. Liu, M. E. Peterson, S. Rajagopalan, Controlling natural killer cell responses: Integration of signals for activation and inhibition. Annu. Rev. Immunol. 31, 227-258 (2013).

15. A. M. Jamieson, A. Diefenbach, C. W. McMahon, N. Xiong, J. R. Carlyle, D. H. Raulet, The role of the NKG2D immunoreceptor in immune cell activation and natural killing. Immunity 17, 19-29 (2002)

16. E. Vivier, E. Tomasello, M. Baratin, T. Walzer, S. Ugolini, Functions of natural killer cells. Nat. Immunol. 9, 503-510 (2008). 
17. V. Groh, J. Wu, C. Yee, T. Spies, Tumour-derived soluble MIC ligands impair expression of NKG2D and T-cell activation. Nature 419, 734-738 (2002).

18. E. S. Doubrovina, M. M. Doubrovin, E. Vider, R. B. Sisson, R. J. O'Reilly, B. Dupont, Y. M. Vyas, Evasion from NK cell immunity by MHC class I chain-related molecules expressing colon adenocarcinoma. J. Immunol. 171, 6891-6899 (2003).

19. H. Song, J. Kim, D. Cosman, I. Choi, Soluble ULBP suppresses natural killer cell activity via down-regulating NKG2D expression. Cell. Immunol. 239, 22-30 (2006).

20. I. Waldhauer, A. Steinle, Proteolytic release of soluble UL16-binding protein 2 from tumor cells. Cancer Res. 66, 2520-2526 (2006)

21. O. Ashiru, P. Boutet, L. Fernández-Messina, S. Agüera-González, J. N. Skepper, M. Valés-Gómez, H. T. Reyburn, Natural killer cell cytotoxicity is suppressed by exposure to the human NKG2D ligand MICA*008 that is shed by tumor cells in exosomes. Cancer Res. 70, 481-489 (2010).

22. C. Cenciarelli, D. Hou, K. C. Hsu, B. L. Rellahan, D. L. Wiest, H. T. Smith, V. A. Fried, A. M. Weissman, Activation-induced ubiquitination of the T cell antigen receptor. Science 257, 795-797 (1992)

23. R. Paolini, A. Serra, R. Molfetta, M. Piccoli, L. Frati, A. Santoni, Tyrosine kinasedependent ubiquitination of CD16 $\zeta$ subunit in human NK cells following receptor engagement. Eur. J. Immunol. 29, 3179-3187 (1999).

24. G. M. Di Guglielmo, C. Le Roy, A. F. Goodfellow, J. L. Wrana, Distinct endocytic pathways regulate TGF- $\beta$ receptor signalling and turnover. Nat. Cell Biol. 5, 410-421 (2003)

25. R. Molfetta, F. Gasparrini, G. Peruzzi, L. Vian, M. Piccoli, L. Frati, A. Santoni, R. Paolini, Lipid raft-dependent $F_{c \varepsilon R I}$ ubiquitination regulates receptor endocytosis through the action of ubiquitin binding adaptors. PLOS One 4, e5604 (2009).

26. R. Molfetta, L. Quatrini, C. Capuano, F. Gasparrini, B. Zitti, A. Zingoni, R. Galandrini, A. Santoni, R. Paolini, c-Cbl regulates MICA- but not ULBP2-induced NKG2D downmodulation in human NK cells. Eur. J. Immunol. 44, 2761-2770 (2014)

27. S. Polo, P. P. Di Fiore, Endocytosis conducts the cell signaling orchestra. Cell 124 897-900 (2006)

28. A. Sorkin, M. von Zastrow, Endocytosis and signalling: Intertwining molecular networks. Nat. Rev. Mol. Cell Biol. 10, 609-622 (2009).

29. A. V. Vieira, C. Lamaze, S. L. Schmid, Control of EGF receptor signaling by clathrinmediated endocytosis. Science 274, 2086-2089 (1996).

30. K. A. DeFea, J. Zalevsky, M. S. Thoma, O. Déry, R. D. Mullins, N. W. Bunnett, $\beta$-Arrestindependent endocytosis of proteinase-activated receptor 2 is required for intracellula targeting of activated ERK1/2. J. Cell Biol. 148, 1267-1281 (2000).

31. C. L. Howe, J. S. Valletta, A. S. Rusnak, W. C. Mobley, NGF signaling from clathrincoated vesicles: Evidence that signaling endosomes serve as a platform for the RasMAPK pathway. Neuron 32, 801-814 (2001).

32. L. M. Luttrell, F. L. Roudabush, E. W. Choy, W. E. Miller, M. E. Field, K. L. Pierce, R. J. Lefkowitz, Activation and targeting of extracellular signal-regulated kinases by $\beta$-arrestin scaffolds. Proc. Natl. Acad. Sci. U.S.A. 98, 2449-2454 (2001).

33. D. Teis, W. Wunderlich, L. A. Huber, Localization of the MP1-MAPK scaffold complex to endosomes is mediated by p14 and required for signal transduction. Dev. Cell 3 803-814 (2002)

34. E. Galperin, A. Sorkin, Endosomal targeting of MEK2 requires RAF, MEK kinase activity and clathrin-dependent endocytosis. Traffic 9, 1776-1790 (2008).

35. A. Chaturvedi, R. Martz, D. Dorward, M. Waisberg, S. K. Pierce, Endocytosed BCRs sequentially regulate MAPK and Akt signaling pathways from intracellular compartments. Nat. Immunol. 12, 1119-1126 (2011).

36. N. Parameswaran, G. Enyindah-Asonye, N. Bagheri, N. B. Shah, N. Gupta, Spatial coupling of JNK activation to the B cell antigen receptor by tyrosine-phosphorylated ezrin. J. Immunol. 190, 2017-2026 (2013).

37. I. A. Yudushkin, R. D. Vale, Imaging T-cell receptor activation reveals accumulation of tyrosine-phosphorylated CD3 $\zeta$ in the endosomal compartment. Proc. Natl. Acad. Sci. U.S.A 107, 22128-22133 (2010).

38. D. D. Billadeau, T cell activation at the immunological synapse: Vesicles emerge for LATer signaling. Sci. Signal. 3, pe16 (2010)

39. T. Willinger, M. Staron, S. M. Ferguson, P. De Camilli, R. A. Flavell, Dynamin 2-dependent endocytosis sustains T-cell receptor signaling and drives metabolic reprogramming in T lymphocytes. Proc. Natl. Acad. Sci. U.S.A. 112, 4423-4428 (2015).

40. R. Paolini, R. Molfetta, M. Piccoli, L. Frati, A. Santoni, Ubiquitination and degradation of Syk and ZAP-70 protein tyrosine kinases in human NK cells upon CD16 engagement Proc. Natl. Acad. Sci. U.S.A. 98, 9611-9616 (2001)

41. Y. T. Bryceson, M. E. March, H.-G. Ljunggren, E. O. Long, Synergy among receptors on resting NK cells for the activation of natural cytotoxicity and cytokine secretion. Blood 107, 159-166 (2006).

42. M. Milella, A. Gismondi, P. Roncaioli, L. Bisogno, G. Palmieri, L. Frati, M. G. Cifone, A. Santoni, CD16 cross-linking induces both secretory and extracellular signal-regulated kinase (ERK)-dependent cytosolic phospholipase A2 (PLA2) activity in human natural killer cells: Involvement of ERK, but not PLA2, in CD16-triggered granule exocytosis. J. Immunol. 158, 3148-3154 (1997)

43. S. Wei, A. M. Gamero, J. H. Liu, A. A. Daulton, N. I. Valkov, J. A. Trapani, A. C. Larner, M. J. Weber, J. Y. Djeu, Control of lytic function by mitogen-activated protein kinase/ extracellular regulatory kinase 2 (ERK2) in a human natural killer cell line: Identification of perforin and granzyme B mobilization by functional ERK2. J. Exp. Med. 187, 1753-1765 (1998).

44. F. Mainiero, A. Gismondi, A. Soriani, M. Cippitelli, G. Palmieri, J. Jacobelli, M. Piccoli, L. Frati, A. Santoni, Integrin-mediated Ras-extracellular regulated kinase (ERK) signaling regulates interferon $\gamma$ production in human natural killer cells. J. Exp. Med. 188, 1267-1275 (1998)

45. R. Trotta, K. A. Puorro, M. Paroli, L. Azzoni, B. Abebe, L. C. Eisenlohr, B. Perussia Dependence of both spontaneous and antibody-dependent, granule exocytosis-mediated NK cell cytotoxicity on extracellular signal-regulated kinases. J. Immunol. 161, 6648-6656 (1998)

46. X. Chen, D. S. Allan, K. Krzewski, B. Ge, H. Kopcow, J. L. Strominger, CD28-stimulated ERK2 phosphorylation is required for polarization of the microtubule organizing cente and granules in YTS NK cells. Proc. Natl. Acad. Sci. U.S.A. 103, 10346-10351 (2006).

47. E. Macia, M. Ehrlich, R. Massol, E. Boucrot, C. Brunner, T. Kirchhausen, Dynasore, a cell-permeable inhibitor of dynamin. Dev. Cell 10, 839-850 (2006).

48. P. Roda-Navarro, H. T. Reyburn, The traffic of the NKG2D/Dap10 receptor complex during natural killer (NK) cell activation. J. Biol. Chem. 284, 16463-16472 (2009).

49. K. Ogasawara, J. A. Hamerman, H. Hsin, S. Chikuma, H. Bour-Jordan, T. Chen, T. Pertel, C. Carnaud, J. A. Bluestone, L. L. Lanier, Impairment of NK cell function by NKG2D modulation in NOD mice. Immunity 18, 41-51 (2003).

50. T. Horng, J. S. Bezbradica, R. Medzhitov, NKG2D signaling is coupled to the interleukin 15 receptor signaling pathway. Nat. Immunol. 8, 1345-1352 (2007).

51. J. C. Kagan, T. Su, T. Horng, A. Chow, S. Akira, R. Medzhitov, TRAM couples endocytosis of Toll-like receptor 4 to the induction of interferon- $\beta$. Nat. Immunol. 9, 361-368 (2008).

52. S. Rajagopalan, Y. T. Bryceson, S. P. Kuppusamy, D. E. Geraghty, A. van der Meer, I. Joosten E. O. Long, Activation of NK cells by an endocytosed receptor for soluble HLA-G. PLOS Biol. 4, e9 (2006).

53. S. M. S. Miah, A. K. Purdy, N. B. Rodin, A. W. MacFarlane IV, J. Oshinsky, D. A. Alvarez-Arias, K. S. Campbell, Ubiquitylation of an internalized killer cell Ig-like receptor by Triad3A disrupts sustained NF-kB signaling. J. Immunol. 186, 2959-2969 (2011).

54. L. Ge, Y. Ly, M. Hollenberg, K. DeFea, A $\beta$-arrestin-dependent scaffold is associated with prolonged MAPK activation in pseudopodia during protease-activated receptor-2 induced chemotaxis. J. Biol. Chem. 278, 34418-34426 (2003).

55. K. Honda, Y. Ohba, H. Yanai, H. Negishi, T. Mizutani, A. Takaoka, C. Taya, T. Taniguchi, Spatiotemporal regulation of MyD88-IRF-7 signalling for robust type-I interferon induction. Nature 434, 1035-1040 (2005).

56. S. Hisata, T. Sakisaka, T. Baba, T. Yamada, K. Aoki, M. Matsuda, Y. Takai, Rap1-PDZGEF1 interacts with a neurotrophin receptor at late endosomes, leading to sustained activation of Rap1 and ERK and neurite outgrowth. J. Cell Biol. 178, 843-860 (2007).

57. J. Huynh, M. Q. Kwa, A. D. Cook, J. A. Hamilton, G. M. Scholz, CSF-1 receptor signalling from endosomes mediates the sustained activation of Erk1/2 and Akt in macrophages. Cell. Signal. 24, 1753-1761 (2012)

58. C. Fionda, M. P. Abruzzese, A. Zingoni, A. Soriani, B. Ricci, R. Molfetta, R. Paolini, A. Santoni, M. Cippitelli, Nitric oxide donors increase PVR/CD155 DNAM-1 ligand expression in multiple myeloma cells: Role of DNA damage response activation. BMC Cancer 15, 17 (2015).

59. F. Gasparrini, R. Molfetta, L. Quatrini, L. Frati, A. Santoni, R. Paolini, Syk-dependent regulation of Hrs phosphorylation and ubiquitination upon FceRI engagement: Impact on Hrs membrane/cytosol localization. Eur. J. Immunol. 42, 2744-2753 (2012).

60. C. Capuano, R. Paolini, R. Molfetta, L. Frati, A. Santoni, R. Galandrini, PIP2-dependent regulation of Munc13-4 endocytic recycling: Impact on the cytolytic secretory pathway. Blood 119, 2252-2262 (2012).

Acknowledgments: We are grateful to L. L. Lanier for providing us the Ba/F3-MICA and $\mathrm{Ba} / \mathrm{F} 3-\mathrm{CD} 48$ cell lines, to L. Palmieri for precious advice on statistical analysis, and to B. Milana for her technical assistance. Funding: This work was supported by grants from the Italian Association for Cancer Research (AIRC), the Italian Ministry for University and Research (MIUR-FIRB; PRIN/20103FMJEN to A.S.; PRIN/2010NECHBX_004 to M.C.), and the Center of Excellence (BEMM). Author contributions: L.Q. performed the experiments, analyzed the results, and contributed to designing research and writing the manuscript; R.M. performed experiments, analyzed results, and contributed to designing research; B.Z. performed experiments and analyzed results; G.P. performed cell sorting; C.C. and C.F. contributed to the experiments; R.G. and M.C. contributed to the experiments and critically reviewed the manuscript; and A.S. and R.P. contributed equally to designing research and writing the manuscript. Competing interests: The authors declare that they have no competing interests.

Submitted 2 April 2015

Accepted 9 October 2015

Final Publication 27 October 2015

10.1126/scisignal.aab2724

Citation: L. Quatrini, R. Molfetta, B. Zitti, G. Peruzzi, C. Fionda, C. Capuano, R. Galandrini, M. Cippitelli, A. Santoni, R. Paolini, Ubiquitin-dependent endocytosis of NKG2D-DAP10 receptor complexes activates signaling and functions in human NK cells. Sci. Signal. 8 , ra108 (2015) 
Science Signaling

MAAAS
Ubiquitin-dependent endocytosis of NKG2D-DAP10 receptor complexes activates signaling and functions in human NK cells Linda Quatrini, Rosa Molfetta, Beatrice Zitti, Giovanna Peruzzi, Cinzia Fionda, Cristina Capuano, Ricciarda Galandrini, Marco Cippitelli, Angela Santoni and Rossella Paolini (October 27, 2015) Science Signaling 8 (400), ra108. [doi: 10.1126/scisignal.aab2724]

The following resources related to this article are available online at http://stke.sciencemag.org. This information is current as of October 28, 2015.

Article Tools Visit the online version of this article to access the personalization and article tools:

http://stke.sciencemag.org/content/8/400/ra108

Supplemental Materials

Related Content

\section{References}

Permissions
"Supplementary Materials"

http://stke.sciencemag.org/content/suppl/2015/10/23/8.400.ra108.DC1

The editors suggest related resources on Science's sites: http://stke.sciencemag.org/content/sigtrans/6/285/ra62.full http://stke.sciencemag.org/content/sigtrans/5/232/ra49.full http://stke.sciencemag.org/content/sigtrans/4/167/ra21.full http://www.sciencemag.org/content/sci/348/6230/136.full http://www.sciencemag.org/content/sci/348/6230/45.full http://www.sciencemag.org/content/sci/341/6142/186.full http://stm.sciencemag.org/content/scitransmed/6/231/231ra49.full http://stm.sciencemag.org/content/scitransmed/7/306/306ec160.full http://stm.sciencemag.org/content/scitransmed/7/297/297ra115.full

This article cites 60 articles, 28 of which you can access for free at: http://stke.sciencemag.org/content/8/400/ra108\#BIBL

Obtain information about reproducing this article: http://www.sciencemag.org/about/permissions.dtl

Science Signaling (ISSN 1937-9145) is published weekly, except the last December, by the American Association for the Advancement of Science, 1200 New York Avenue, NW, Washington, DC 20005. Copyright 2015 by the American Association for the Advancement of Science; all rights reserved. 